\title{
Foreign Body Aspiration in Adult: Analysis of 28 Cases
}

\section{Cengiz Özdemir ${ }^{1}$, Sinem Nedime Sökücü ${ }^{1}$, Levent Karasulu ${ }^{1}$, Songül Büyükkale², Levent Dalar ${ }^{3}$}

${ }^{1}$ Clinic of Chest Diseases, Yedikule Chest Diseases and Chest Surgery Training and Research Hospital, İstanbul ${ }^{2}$ Clinic of Chest Surgery, Yedikule Chest Diseases and Chest Surgery Training and Research Hospital, İstanbul ${ }^{3}$ Department of Chest Diseases, İstanbul Bilim University Faculty of Medicine, İstanbul

\begin{abstract}
Objective: The aim of our study is to discuss our experience with foreign body aspirations in our Interventional Pulmonology Unit.

Methods: Patients who were referred to our Interventional Pulmonology Unit between January 2008 to November 2014 for foreign body aspiration and whom foreign body was sentential by intervention were included. Data were used from a retrospective analysis.

Results: From the 28 patients, $64.3 \%$ of them were women and mean age of the patients were $43.5 \pm 21.54$ years. Most common presenting symptom was cough (96.3\%). Half of the patients were presented in 24 hours after the procedure. From the 5 patients that have undergone diagnostic broncoscopy by fiberoptic bronchoscope, foreign body was removed in 3 of them. Rigid bronchoscopy was done in 25 (89.3\%) of the patients. In 3 of the patients foreign body cannot be detected by bronchoscopy and removed by surgery. $67.9 \%$ of the foreign bodies that were removed were inorganic in nature.

Conclusion: Bronchoscopic approaches are effective to decrease mortality and morbidity for the diagnosis and treatment of foreign body aspirations in adults. Rigid bronchoscopic approach should be the first choice in foreign body aspirations but fiberoptic bronchoscopy can also be used in selective cases by experienced physicians.
\end{abstract}

Keywords: Cryotherapy, foreign body, rigid bronchoscopy

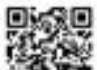

Received Date: 20.11.2014

Accepted Date: 10.01.2015

Available Online Date: 27.02.2015

Address for correspondence

Cengiz Özdemir, Clinic of Chest Diseases, Yedikule

Chest Diseases and Chest Surgery Training and

Research Hospital, İstanbul, Turkey

E-mail: cengizoz78@yahoo.com

(1) (2) This work is licensed under a Creative Commons Attribution-NonCommercia 4.0 International License.

DOI: $10.5152 /$ ejp.2015.36844

-Available online at www.eurasianjpulmonol.com

\section{INTRODUCTION}

Foreign body aspiration in the airway is a life-threatening medical emergency and requires early intervention. Although often seen in childhood, it can be seen in adults leading to different symptoms depending on the place where the foreign body is settled in the airway. When foreign bodies obstruct the main airway, it causes asphyxia with acute respiratory failure, whereas in more distal airway obstruction, symptoms such as coughing, shortness of breath, and hemoptysis may be experienced $(1,2)$. In cases where aspiration is not overt and with a delay in diagnosis, postobstructive pneumonia, atelectasis, bronchiectasis, and granulation tissue formation can be observed $(3,4)$.

Today, the use of bronchoscopic techniques for the removal of foreign bodies is the basic method. Bronchoscopy was used for the first time in 1897 with a rigid bronchoscope for the removal of foreign bodies from the trachea, and since then, rigid bronchoscopic techniques have been in progress and have been widely used for this purpose. Later, with the introduction and spread of flexible bronchoscopy, flexible bronchoscopy has also been used in the removal of foreign bodies (5). Today rigid bronchoscopy is still used in the treatment of foreign body aspiration, especially as the main treatment in children, and maintains its importance. However, since it requires experience, general anesthesia, and many different types of equipment, today, rigid bronchoscopy is mostly used by thoracic and pediatric surgeons. 
The aim of this retrospective study is to discuss our experience with foreign body aspiration in adult patients who received treatment in our Interventional Pulmonology Unit.

\section{METHODS}

In our study, patients who were referred to our Interventional Pulmonology Unit between January 2008 and November 2014 because of foreign body aspiration and who underwent a surgery and thus had conclusive foreign body aspiration were included. Data were retrospectively obtained by examining the patient's file.

Before flexible bronchoscopy was performed in the bronchoscopy unit, lidocaine ( $\max 8 \mathrm{mg} / \mathrm{kg}$ ) as a topical anesthetic and if needed, intravenous midazolam $(0.05 \mathrm{mg} / \mathrm{kg})$ for conscious sedation were administered. All patients underwent endoscopy with the oral approach.

Before rigid bronchoscopy, following pre-anesthesia consultation and necessary tests, in the operating room, rigid bronchoscopy (Karl Storz Instruments, Germany) under intravenous anesthesia was performed. If required, distal airways were evaluated with flexible bronchoscopy (Olympus BF 1T150, Tokyo, Japan) through rigid bronchoscopy. Foreign objects detected in the bronchoscopic examination were removed using alligator forceps, grasping forceps, biopsy forceps, and basket forceps. When the foreign body-induced granulation tissue was detected, cryotherapy (ERBE, Tubingen, Germany) was used. Informed consent was obtained from all patients before the procedure.

Of patient data, age, sex, symptoms, application time after aspiration (early: patients presented within $24 \mathrm{~h}$, late: patients presented after $24 \mathrm{~h}$ ), predisposing factors, presence of radiological symptoms, endoscopic methods used in foreign body removal, removed foreign bodies, patients in whom the procedure failed and underwent surgery, and the data required for control bronchoscopy after foreign body removal were analyzed.

\section{Statistical Analysis}

For statistical analysis, descriptive statistics in Statistical Package for the Social Sciences (SPSS, Chicago, IL, USA) 16.0 program were used.

\section{RESULTS}

In the study, 18 of 28 patients (64.3\%) were females, and the average age was $43.5 \pm 21.54$ years (age range $15-84$ ). In the anamnesis of all cases, there was foreign body aspiration history. The history of aspiration was personally taken from all patients, except one with schizophrenia. The symptoms and other characteristics of the patients during admission are shown in Table 1. The most common symptom was coughing with $96.3 \%$. Half of the patients were admitted to the hospital in the first $24 \mathrm{~h}$ of aspiration and were intervened. Predisposing factors for aspiration were detected in four patients (three patients had aspirated tracheostomized and speech cannula piece, one patient had been receiving treatment for a long time because of schizophrenia). On radiological imaging, nine patients $(32.1 \%)$ with atelectasis, nine (32.1\%) with pneumonic infiltration, and five (17.8\%) with unilateral hyperaeration were detected. In 15 (53.5\%) patients, the aspirated radiopaque foreign body was detected using imaging methods.

Diagnostic flexible bronchoscopy because of foreign body aspiration was performed in 3 of 5 patients, and foreign bodies were successfully obtained with flexible bronchoscopy. The foreign bodies extracted from these three patients were needles. Rigid bronchoscopy had to be performed on two patients in order for foreign body removal. The aspirated foreign bodies that could not be removed by flexible bronchoscopy were a peanut in one case and speech device piece in the other patient. Rigid bronchoscopy was performed for a total of 25 cases. In all patients who underwent rigid bronchoscopy, detailed evaluation of the distal airways during operation, secretion clearance, and in some cases, a flexible bronchoscope passing through a rigid tube for cryotherapy administration were performed (Table 1) (Figure 1-3).

The localization of aspirated foreign bodies in the airway is shown in Table 2. The foreign bodies were detected in the right bronchial system in 14 patients, in the left bronchial in 13 patients, and in the trachea in one patient. Nine of aspirated foreign bodies (32.1\%) were organic and 19 (67.9\%) were inorganic substances (Table 3). The most common aspirated foreign body was a needle (in eight patients, $32 \%)$. All eight patients who aspirated needles were female, and in six (21.4\%) of these patients, the needle that was aspirated was used to attach their headscarves. The foreign bodies were successfully removed from the airway with flexible and rigid bronchoscopy in 25 patients (89.3\%). No mortality and complications were observed in patients who underwent bronchoscopy.

On bronchoscopic examination, in three patients who aspirated needles, no foreign body was detected in the airways, and all these

Table 1. Demographic features of patients, symptoms for admission, and procedures performed

\begin{tabular}{|c|c|c|}
\hline Features & Number of patients & $\%$ \\
\hline Age & $43.5 \pm 21.54$ & \\
\hline Gender (F/M) & $18 / 10$ & $64.3 / 35.7$ \\
\hline \multicolumn{3}{|l|}{ Symptoms* } \\
\hline Cough & 26 & 96.3 \\
\hline Dyspnea & 13 & 46.4 \\
\hline Phlegm & 7 & 25.9 \\
\hline Hemoptysis & 3 & 11.1 \\
\hline Chest pain & 1 & 3.7 \\
\hline \multicolumn{3}{|c|}{ Time of admission } \\
\hline Early (<24 h) & 14 & 50 \\
\hline Late (>24 h) & 14 & 50 \\
\hline \multicolumn{3}{|c|}{ Flexible bronchoscopy** } \\
\hline Diagnostic & 5 & 17.9 \\
\hline Treatment & 3 & 10.7 \\
\hline \multicolumn{3}{|c|}{ Rigid bronchoscopy } \\
\hline Treatment & 25 & 89.3 \\
\hline \multicolumn{3}{|c|}{$\begin{array}{l}\text { * In a patient who had an aspirated tooth in the airway during intubation } \\
\text { in the intensive care unit, symptoms were left out of evaluation because } \\
\text { of the application of sedation } \\
\text { ** Foreign body was removed in } 3 \text { of } 5 \text { patients who underwent flexible } \\
\text { bronchoscopy for diagnosis, and rigid bronchoscopy was performed in } \\
\text { two patients }\end{array}$} \\
\hline
\end{tabular}



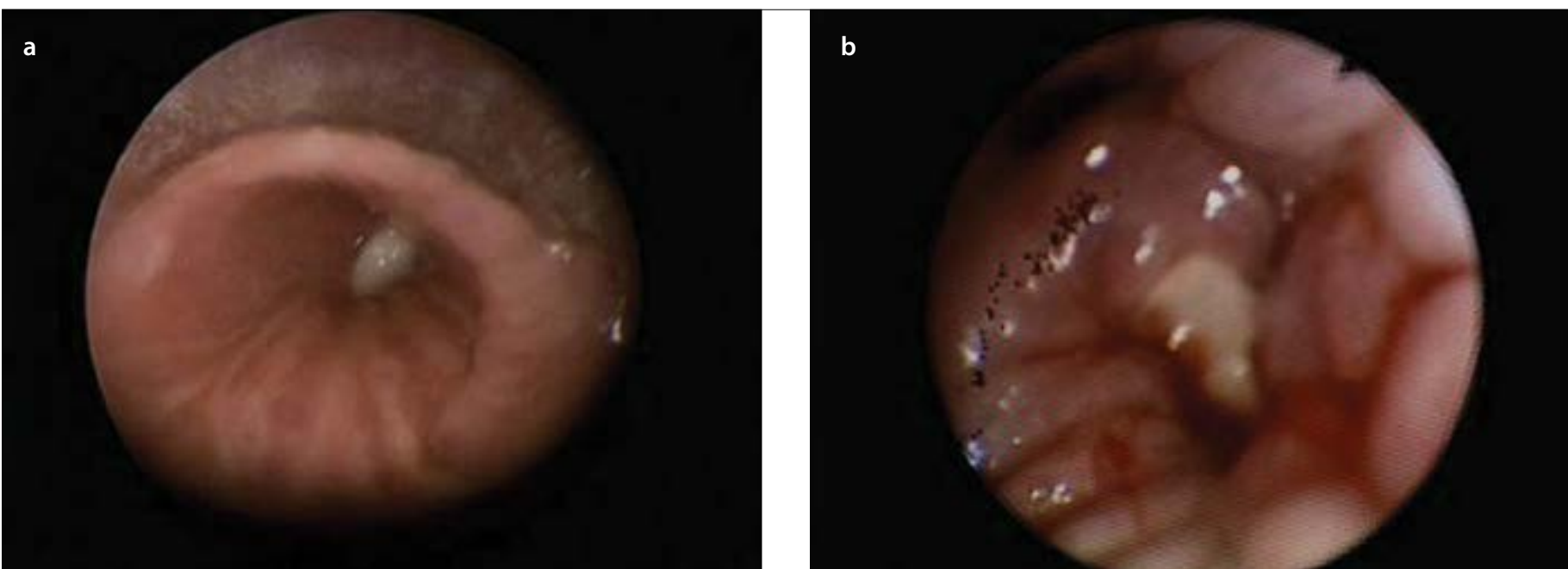

Figure 1. a, b. Aspirated bone piece in the entry of the right lower lobe bronchus (a); formation of minimal granulation around it (b)
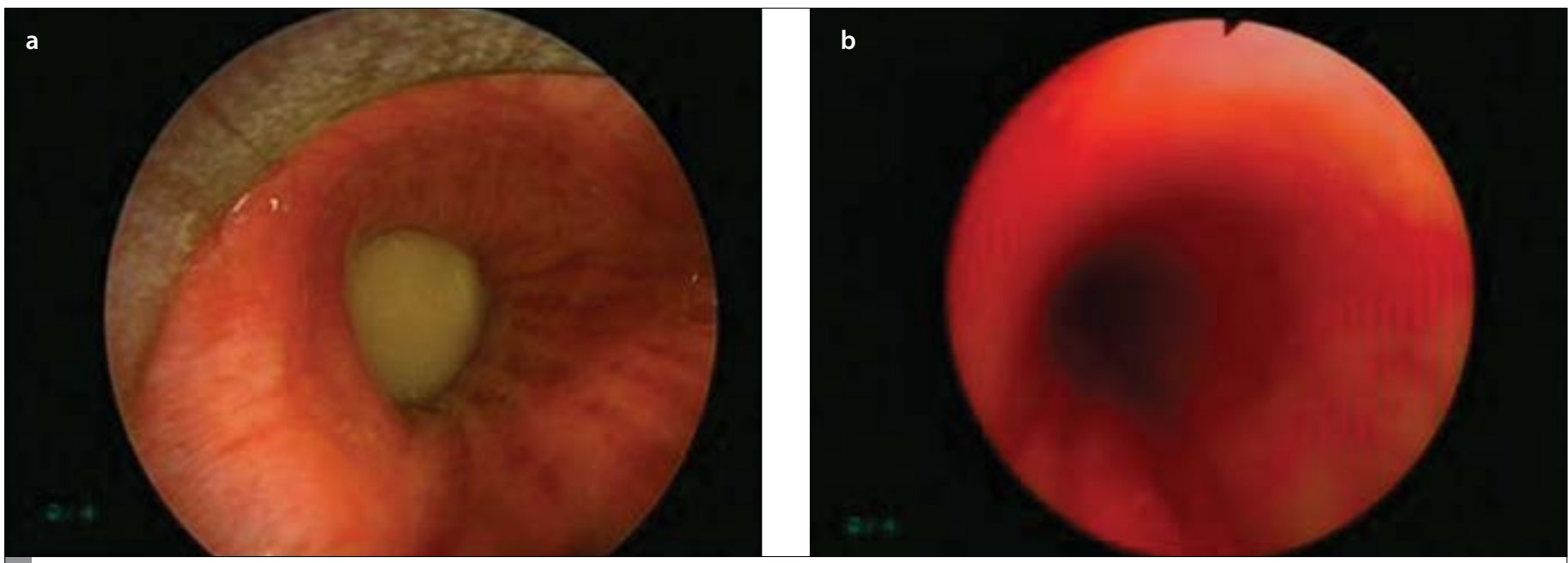

Figure 2. a, b. Foreign body completely obstructing the left main bronchus (distal; chick pea) (a); edema and hyperemia in the distal airway after the removal of foreign body (b)
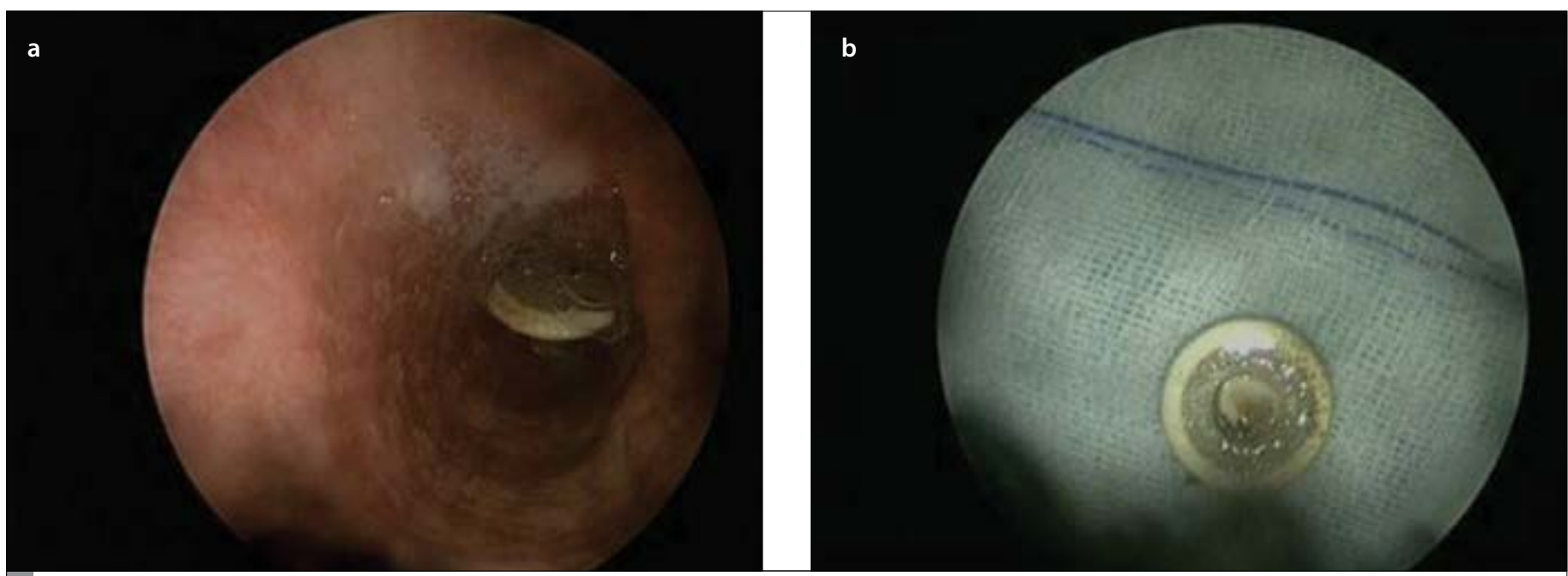

Figure 3. a, b. In a patient tracheostomized because of laryngeal carcinoma; the piece of speech device aspirated in the right intermediate bronchus (proximal) (a); foreign body removed by rigid bronchoscopy (b) 
Table 2. Localizations of aspirated foreign bodies in the airway

\begin{tabular}{|l|c|c|}
\hline Features & Number of patients & $\%$ \\
\hline Trachea & 1 & 3.6 \\
\hline Uight bronchial system & 2 & 7.2 \\
$\quad$ Intermediary bronchus & 5 & 17.9 \\
\hline Lower lobe & 7 & 25 \\
\hline Left bronchial system & & \\
\hline \multicolumn{1}{|l|}{ Main bronchus } & 8 & 28.6 \\
Upper lobe & 2 & 7.2 \\
\hline Lower lobe & 3 & 10.7 \\
\hline
\end{tabular}

* No foreign body was bronchoscopically observed in the airway in 3 of 28 patients, and foreign bodies were surgically removed in the left upper lobe of one patient and in the right lower lobe of two patients

Table 3. Distribution of foreign bodies removed by bronchoscopy $(n=25)^{*}$

\begin{tabular}{|l|c|c|}
\hline Foreign bodies & Number & $\%$ \\
\hline Organic & 9 & 36 \\
Dried nuts & 5 & 20 \\
Bone & 2 & 8 \\
Grape & 1 & 4 \\
\hline Tooth & 1 & 4 \\
\hline Inorganic & 16 & 64 \\
\hline Pin & 8 & 32 \\
\hline Pencil cap & 2 & 8 \\
\hline Ear ring & 1 & 4 \\
\hline Piece of speech device & 3 & 12 \\
\hline Piece of a plastic object & 2 & 8 \\
\hline
\end{tabular}

*In three patients with aspirated pin, the foreign bodies were removed through operation by the department of thoracic surgery because they could not been reached via bronchoscopy. Therefore, these three patients were not included in the table

patients underwent both rigid and flexible bronchoscopy. In these three patients, because foreign bodies could not be removed by bronchoscopy, they were removed in thoracic surgical operations. In three patients (10.7\%), foreign body-induced granulation tissue was present in the airway, and these patients underwent flexible bronchoscopy with cryotherapy for two sessions. Complete regression was observed in the granulation tissue in all three patients. Because of the development of bronchiectasis and destruction of parenchyma in the right lower lobe, right lower lobectomy had to be performed in one case.

\section{DISCUSSION}

Bronchoscopic methods used in the evaluation of the tracheobronchial tree have been used for decades to treat foreign body aspiration in the airways. The treatment with flexible and rigid bronchoscopic interventions of foreign body aspiration, which causes morbidity and mortality, maintains its importance and is widely used today. In our study, in the Interventional Pulmonology Unit, foreign bodies were successfully removed in $89.3 \%$ of patients who underwent bronchoscopy for foreign body aspiration.

Foreign body aspiration occurs more frequently in childhood than in adulthood. Seven percent of deaths due to accidents among children under the age of four are reported to be induced by foreign body aspiration (5). Because our hospital serves adults, all the patients presented in our study were older than 15 . In adulthood, on the other hand, many predisposing factors for foreign body aspiration have been identified. The most important risk factors are neurological and neuromuscular diseases, psychiatric disorders, alcohol abuse, head trauma, use of drugs causing brain fog, and use of audio prosthetic devices (3). In our study, except for three tracheostomized patients who aspirated audio prosthetic device part was aspirated and one patient treated for schizophrenia, no risk factors were observed for aspiration.

It is reported in literature that foreign body aspiration occurs more frequently in men than in women $(6,7)$. However, unlike literature, in our study, foreign body aspiration was higher in women. The reason is that needles are widely used to attach headscarves in our country. The higher rate among women in publications in our country also supports this situation $(8,9)$. In our study, all eight patients who aspirated needles were female, and these patients used the needles to attach their headscarves.

Aspirated foreign bodies in adults are usually lodged in the distal airways and can cause nonspecific symptoms that may be confused with other diseases before asphyxia occurs. This situation leads to delays in diagnosis, especially in patients where a history of aspiration cannot be taken. In our study, $50 \%$ of the patients were admitted to the hospital after the first $24 \mathrm{~h}$ of the aspiration. In previous studies, up to 15 months of delay between the development of symptoms and diagnosis of aspiration was reported (4). In our study, the patient with the longest period before the detection of foreign body aspiration was four years, and the patient had lobectomy because of the development of bronchiectasis. Because of a history of aspiration, this patient underwent flexible bronchoscopy four years ago. However, because of the granulation tissue growing around the foreign body, the foreign body could not be detected in the bronchoscopic examination, and a biopsy specimen was taken from the granulation tissue. After that stage, patient follow-up was stopped, and when the patient was readmitted because of recurrent pulmonary infections, foreign bodies were detected after rigid bronchoscopic examinations.

Aspirated foreign bodies are classified as organic and inorganic substances. Aspirated foreign objects differ according to age, gender, profession, cultural life, socio-economic status, and diet. Whereas inorganic body aspiration is more frequently seen in adults, organic body aspiration is more common in unindustrialized countries (9-11). Inorganic body aspiration was found in $64 \%$ of our adult patients. Among these, the most common aspirated foreign bodies were needles.

Because of the anatomical features of the bronchial tree, foreign body aspiration is more frequently seen in the right bronchial system 
$(4,8,11)$. The reason for this location is that the right main bronchus is wider and shorter and has more vertical localization than the left main bronchus (9). In our study, it was reported that $50.1 \%$ of aspirated foreign bodies were in the right bronchial system, $46.5 \%$ were in the left bronchial system, and $3.6 \%$ were in the trachea.

Bronchoscopic procedure is the gold standard method for the diagnosis and treatment of foreign body aspiration $(12,13)$. Despite the progress in bronchoscopic techniques in recent years, the removal of foreign bodies from the airway by rigid bronchoscopy is still widely used $(5,14)$. Recently, a growing number of studies on the use of flexible bronchoscopy in the treatment of foreign body aspiration are being published $(3,4,12)$. The success rate with rigid bronchoscopy in the treatment of foreign body aspiration is reported to be $95 \%$, whereas with flexible bronchoscopy, it is between $82.5 \%$ and $98 \%(3,4,12,15$, 16). Both methods are used in the removal of foreign bodies in carefully selected cases despite their advantages and disadvantages. While flexible bronchoscopy is a more acceptable method for patients because it does not require general anesthesia, can be performed under conscious sedation, and does not cause complications such as teeth, vocal cord, and bronchial wall damage, rigid bronchoscopy is more commonly preferred because it provides a larger operation site for foreign body removal, secretion and safer aspiration of blood residue, and the continuation of ventilation during the procedure.

Experience with rigid bronchoscopy methods commonly used in the treatment of foreign body aspiration is usually limited for thoracic and pediatric surgeons. Before the widespread use of flexible bronchoscopy, although rigid bronchoscopy was frequently used in pulmonology bronchoscopy, rigid bronchoscopy is now used in very few health centers by pulmonologists. Although initial evaluations of the patients with foreign body aspiration in the emergency services are mostly performed by pulmonologists, immediate treatment may be insufficient because of inexperience in performing rigid bronchoscopy. Although flexible bronchoscopy methods for the treatment of foreign body aspiration can be performed in centers where rigid bronchoscopy use is not possible, foreign body removal may not be possible at all times, and sufficient experience is also necessary in this regard. Rodrigues et al. (12) reported in their study that in $15 \%$ of patients, aspirated foreign bodies could not be removed with flexible bronchoscopy, and therefore, rigid bronchoscopy had to be performed. Dong et al. (4) stated that they had been unsuccessful with flexible bronchoscopy in removing foreign bodies in $3.5 \%$ of cases and had to perform surgical intervention. The authors stated that in the cases they failed, the foreign bodies had been in the airway for more than a month, and severe hemoptysis with granulation tissue formation was observed in these patients. For the treatment of foreign body aspiration with flexible bronchoscopy, careful selection of patients is important. Especially in the early stage, for patients where the foreign body in the airway is not organized, with no granulation tissue and parenchymal damage symptoms, performing flexible bronchoscopic interventions by experienced hands may be considered as a priority. It is vital to have experience in both rigid and flexible bronchoscopies for physicians who encounter this group of patients. In our unit, these procedures can be performed by a trained and experienced team on rigid and flexible bronchoscopy. Our tendency is to perform rigid bronchoscopy in foreign body aspiration process. It is possible to carefully evaluate distal airways with flexible bronchoscopy through a rigid bronchoscopy. In our study, in three of our patients, foreign bodies were successfully removed with flexible bronchoscopy, and rigid bronchoscopy was performed on all other cases. In $89.3 \%$ of patients, the aspirated body was successfully removed by bronchoscopic intervention, and procedure-related mortality was not observed. Only three patients had to be operated because foreign bodies could not be removed by bronchoscopic intervention.

Postobstructive pneumonia secondary to foreign body, lung abscess, bronchiectasis, and granulation tissue formation can be seen especially in adult patients because of the large number of cases with late admission. Performing rigid bronchoscopy in these cases a provides safe aspiration of secretions and residual bleeding and an opportunity to operate granulation tissue formed around the foreign body with hot and cold endobronchial methods (argon plasma coagulation, laser, cryotherapy) $(17,18)$. In our three patients, foreign body secondary to granulation tissue formation in the airway was detected, and complete regression from granulation tissue was obtained with cryotherapy.

The main limitation of our study was the small number of cases. Despite foreign body aspiration being more frequent in childhood, the data presented in our study cover only adult patients. In addition, the patient data were retrospectively obtained from files, and predisposing factors for aspiration were detected in only four patients (aspiration of tracheostomy and speech cannula in three patients, schizophrenia in one patient). Detailed findings for other probable predisposing factors could not be obtained in the patient files.

\section{CONCLUSION}

Bronchoscopic procedures for the diagnosis and treatment of foreign body aspiration in adult patients are effective in reducing mortality and morbidity. Operations using rigid bronchoscopy should be the first method in foreign body aspiration. However, flexible bronchoscopy can also be used if it is performed by experienced hands and in well-selected patients for the treatment of foreign body aspiration.

Ethics Committee Approval: Study done by retrospective data analyses so ethics commitee approwal was not taken.

Informed Consent: Informed consent was received from all of the patients before the procedures.

Peer-review: Externally peer-reviewed.

Author contributions: Concept - C.Ö., S.N.S., L.K., S.B., L.D.; Design - C.Ö., S.N.S., L.K.; Supervision - L.D.; Resource - C.Ö.; Materials - C.Ö., S.B.; Data Collection and/or Processing - C.Ö., S.N.S., S.B.; Analysis and/or Interpretation - C.Ö.; Literature Search - L.K., S.B., S.N.S.; Writing - C.Ö.; Critical Reviews - L.K., L.D.

Conflict of Interest: No conflict of interest was declared by the authors.

Financial Disclosure: The authors declared that this study has received no financial support.

\section{REFERENCES}

1. Friedman EM. Tracheobronchial foreign bodies. Otolaryngol Clin North Am 2000; 33: 179-85. [CrossRef]

2. Steen $\mathrm{KH}$, Zimmermann T. Tracheobronchial aspiration of foreign bodies in children: a study of 94 cases. Laryngoscope 1990; 100: 525-30 [CrossRef]

3. Mise K, Jurcev Savicevic A, Pavlov N, Jankovic S. Removal of tracheobronchial foreign bodies in adults using flexible bronchoscopy: experience 1995-2006. Surg Endosc 2009; 23: 1360-4. [CrossRef]

4. Dong YC, Zhou GW, Bai C, Huang HD, Sun QY, Huang Y, et al. Removal of tracheobronchial foreign bodies in adults using a flexible bronchoscope: experience with 200 cases in China. Intern Med 2012; 51: 2515-9. [CrossRef] 
5. Dikensoy O, Usalan C, Filiz A. Foreign body aspiration: clinical utility of flexible bronchoscopy. Postgrad Med J 2002; 78: 399-403. [CrossRef]

6. Marquette $\mathrm{CH}$, Martinot $\mathrm{A}$. Foreign body removal in adults and children. In: Bolliger CT, ed. Interventional bronchoscopy. Basel: S Karger AG 2000: 96-107.

7. Carluccio F, Romeo R. Inhalation of foreign bodies: epdemiological data and clinical considerations in the light of statistical review of 92 cases. Acta Otorhinolaryngol Italy 1997; 17: 45-51.

8. Kolbakır F, Keçeligil HT, Ankan A, Erk MK. Yabancı cisim aspirasyonları: Brobkoskopi yapılan 152 olgunun analizi. GKD Cer Derg 1995; 3: 117-20.

9. Cobanoğlu U, Yalçinkaya I. Tracheobronchial foreign body aspirations. Ulus Travma Acil Cerrahi Derg 2009; 15: 493-9.

10. Salcedo L. Foreign body aspiration. Anesthesiol Clin North Am 1998; 16 : 885-92. [CrossRef]

11. Gürsu S, Sırmalı M, Gezer S, Fındık G, Türüt $H$, Aydın E, et al. Yetişkinlerde trakeobronşiyal yabancı cisim aspirasyonları. Turkish JThorac Cardiovasc Surg 2006; 14: 38-41.

12. Rodrigues AJ, Oliveira EQ, Scordamaglio PR, Gregório MG, Jacomelli M, Figueiredo VR. Flexible bronchoscopy as the first-choice method of removing foreign bodies from the airways of adults. J Bras Pneumol 2012; 38: 315-20. [CrossRef]
13. Shlizerman L, Mazzawi S, Rakover Y, Ashkenazi D. Foreign body aspiration in children: the effects of delayed diagnosis. Am J Otolaryngol 2010; 31: 320-4. [CrossRef]

14. Korlacki W, Korecka K, Dzielicki J. Foreign body aspiration in children: diagnostic and therapeutic role of bronchoscopy. Pediatr Surg Int 2011; 27: 833-7. [CrossRef]

15. Soysal $\mathrm{O}$, Kuzucu A, Ulutaş $\mathrm{H}$. Tracheobronchial foerign bodies aspiration: a continuing challenge. Otolaryngol Head Neck Surg 2006; 135 : 223-6. [CrossRef]

16. Ibrahim Sersar S, Hamza UA, AbdelHameed WA, AbulMaaty RA, Gowaeli NN, Moussa SA, et al. Inhaled foreign bodies: management according to early or late presentation. Eur J Cardiothorac Surg 2005; 28: 369-74. [CrossRef]

17. Bolliger CT, Sutedja TG, Strausz J, Freitag L. Therapeutic bronchoscopy with immediate effect: laser, electrocautery, argon plasma coagulation and stents. Eur Respir J 2006; 27: 1258-71. [CrossRef]

18. Mathur PN, Wolf KM, Busk MF, Briete WM, Datzman M. Fiberoptic bronchoscopic cryotherapy in the management of tracheobronchial obstruction. Chest 1996; 110: 718-23. [CrossRef] 